\title{
REPRODUCTIVE HEALTH MANAGEMENT IN COWS AND BUFFALOES: A REVIEW
}

\author{
K. S. ROY ${ }^{1 *}$, A. PURKAYASTHA ${ }^{1}$ AND B. S. PRAKASH ${ }^{2}$ \\ ${ }^{1}$ Stress Physiology Laboratory, ICAR-National Institute of Animal Nutrition and Physiology, \\ Bangalore- 560 030, Karnataka, India \\ ${ }^{2}$ Former Assistant Director General, Indian Council of Agricultural Research, New Delhi-110 001, India
}

\begin{abstract}
The livestock produced in small and large holding agricultural systems are vital component of farming economy in the developing world, particularly in a country like India. There is an enormous effect of impinging climate change towards biotic and abiotic stressors as potential impediment factors for augmentation of reproduction and production across the species of animals. To cope up with the daily demand of nutrition for human population in the form of milk, meat, wool, hide and various byproducts etc, it is highly essential to maintain uninterrupted supply chain following proper reproductive and productive management for these valuable livestock populations throughout the country. The simple, achievable goals are important for a strategic herd reproductive health plan. For maintenance of good reproductive performance prevention of diseases during early post partum period is very important. Well supervised strategic treatment of early postpartum reproductive disorders and systemic use of 'Synch Protocols' during appropriate seasonal condition, nutrition and herd management can improve reproductive efficiency of livestock. Controlled breeding programs can reduce days open and that leads to more economic return to the farmers. Maintenance of health, superior reproductive and productive status of animals is important for driving growth in animal husbandry sector.
\end{abstract}

Key words: Buffaloes, Cows, Health management, Reproductive problems, Synch protocols

\section{Introduction}

In spite of the huge population of cattle and buffalo in India, their productivity is very low due to constraints of disease, nutrition, poor management and pitiable reproductive performance of different breeds of cows and buffaloes. The major problem of dairy cows and buffaloes in regard to reproductive performance are abortion, dystocia, retained placenta, uterine and vaginal fetal membrane, acyclicity, anestrous, repeat breeding, uterine and vaginal prolapsed etc. Further, the reproductive health problems causes enormous economic loss to the dairy farmers as it leads to slower uterine involution, prolonged inter-conception and calving interval period, high cost of medication, reduction in milk production and early depreciation of potentially useful cows and buffaloes. For better reproductive management programme, we must have definable goals. Simple and attainable goals should provide the foundation of planned herd health and should be reliable with profitable dairying. This may include: (a) the heifers should first conceive at approximately 24-36 months of age, (b) calving interval should be of at least within 12 to 13 months, (c) ensure that at least $90 \%$ of the cows are bred back to produce another calf crop, (d) keep the cows in the herd as long as they are profitable. And with this view, one should plan a herd-health programme that focuses on preventing diseases, particularly during the prepartum and early postpartum period, incorporating management practices to get cows back to pregnancy promptly after the voluntary

\footnotetext{
"Corresponding Author
} 
waiting period, and implementing a strategy for dealing with the problematic animals. Besides the above factors, the abiotic stresses and mainly the thermoregulatory mechanisms plays a pivotal role for augmentation of reproduction and production in livestock (Roy and Collier, 2012). Hence, the focus to improve reproduction in animals should be on administering appropriate treatments in pre and post partum period, minimizing weight loss in the postpartum cow, controlled breeding programmes, treating anestrous and repeat breeders with appropriate therapy etc (Annual Report, AICRP-NIANP, 2015 to 2019).

\section{Common reproductive diseases}

It is well accepted that the disease can be a deterring factor in the success of reproduction in animals. For successful production of offspring the animal should be free of reproductive diseases. The outbreak of sexually transmitted diseases can be quite large if they are spread by one male animal and naturally mating with several female animals. In addition, these diseases can also be spread by not properly cleaning equipment during the period of artificial insemination (AI). A common sexually transmitted disease in cattle, sheep etc is vibriosis. The vibriosis can cause infertility, abortion and other physiological problems. The general infectious disease is caused by pathogens, such as viruses, bacteria, and parasites etc. Unlike sexually transmitted diseases, the infectious diseases can spread without sexual contact and can infect all animals in a herd at the same time. The results of infectious diseases include infertility, abortion, disrupted reproductive cycles and other abrasive effects. Many infectious reproductive diseases can be found in domesticated and wild animals that includes brucellosis, tuberculosis, and leptospirosis etc. These diseases can be transmitted through contact between diseased animals. Management practices that prevent reproductive diseases include proper sanitation of breeding equipment, limited exposure to outside animals and utilization of artificial insemination and most importantly by scheduled vaccination of the herd. Vaccination against reproductive disease can be highly effective if given at the appropriate time and should always be done prior to the breeding season and to any new animal in the herd. The vaccination cannot cure the diseases but can control them. Other measures are isolating infected animals for certain period, removing the animal from the breeding program, or entirely culling the animal from the herd. Animals with reproductive diseases should be treated, the moment initial signs of the disease is observed, under the supervision of a veterinarian and subsequently eliminated from the herd if the disease persists (Web link: mishicotffa.org/ uploads/2/3/2/7/23271034/repro_problems.pdf).

\section{Reproductive management around calving}

From reproductive health viewpoint, the most critical period in a cow's life is the period from four weeks before and after calving. Health disorders during this period seem to occur as very critical. One disorder tends to lead to another, so that eventually the cow may experience several problems before regaining her health. In general it has been observed that difficulties during parturition leads to the occurrence of retained fetal membranes, higher incidences of metritis or endometritis, lower feed intake, reduced milk production and increased metabolic disorders. The ultimate outcome is poor performance in terms of calf survivability, milk yield, reproductive performance, and survivability of the cow in the herd. Regardless of how well cows are managed during the dry period, if they are not provided with a good environment at the time of calving, they are likely to experience postpartum health problems that will lower milk yield and reproductive performance. If weather permits, the cows should be calved outside of the shed in a dry area. If not, then cows should calve in a well-bedded stall or on a bedding pack. Straw is the most preferred bedding material in the calving area because it absorbs more moisture than other bedding materials. And due to its larger particle size the potential risk of its uptake into the reproductive tract is minimized. In general, clinical problems during and after calving, like abnormal discharges, poor health etc. prevents 
proper involution of the reproductive tract. Further, the poor uterine involution leads to reduced long-term reproductive performance of animals (Oltenacu et al., 1983).

\section{Postpartum care for good reproductive performance}

The well managed cows will come to estrous cycle during the second to fourth week after calving. The cows, those experience health problems at calving and having severe negative energy balance after calving will show a delay in reviving its reproductive cycle. It has been reported a negative relationship between energy balance during the first 20 days after calving and first ovulation. This is good indicator of nutritional status of a herd with beginning of estrous cycle after calving of cows. If this exceeds about $25 \%$, then the feeding program needs to be examined carefully to improve energy intake and reduce the duration of negative energy balance. The cows that experience severe losses in body condition during the postpartum period may begin estrous cycle normally, but still experience low fertility during the breeding period (Butler and Smith, 1989; Britt, 1991; Canfield and Butler, 1991).

\section{Treating postpartum disorders}

The conventional uses of intrauterine antibiotic treatments for postpartum metritis possessed a questionable effectiveness (Ferry, 1994). The uncontrolled use of antibiotics during lactation may lead to residues in milk and meat; therefore, alternative methods for treating metritis are highly suggested. The experimental evidences showed that some reproductive hormones, like prostaglandins and $\mathrm{GnRH}$, may be useful for improving postpartum reproductive performance, particularly in cows and buffaloes that experience dystocia or metritis. But the use of hormones by veterinary practitioners should be consistent with the available regulations.

Retained placenta: The evidences are available that long-acting prostaglandin agonists can reduce the duration of placental retention if administered during the first few hours after calving (Garcia et al., 1989). The prostaglandin could eradicate residual progesterone from a corpus luteum (CL) that had not completely regressed prior to parturition, but if we assume that this is the mechanism, then one would expect shorter-acting prostaglandins to be effective. The literature in this area is too inconsistent to recommend the routine use of prostaglandin agonists after calving, except in certain situations such as with induced calving, where the incidence of retained placenta would be expected to be high (Garcia et al., 1989).

Dystocia: The administration of $\mathrm{PGF}_{2 \alpha}$ analogues at one or two weeks postpartum or GnRH at two weeks postpartum may be beneficial for initiating estrous cycles and reducing interval to first service and days open (Etherington et al., 1994; Risco et al., 1994). The uses of this treatment have been effectively carried out in field condition and have shown equal efficiency in cows that have a history of dystocia and other related problems during calving. The different field trials have proved that prostaglandins alone are probably as effective as the GnRH-prostaglandin combination. In general, the cows that have experienced normal estrous cycle at postpartum are more likely to conceive at first service and require fewer services per conception than anestrous cows. So the effect of $\mathrm{PGF}_{2 \alpha}$ and GnRH in cows with dystocia and retained placenta may be primarily through the earlier cyclicity and better uterine involution associated with recurring estrous cycles.

Cystic follicles: The GnRH or human chorionic gonadotropin (hCG) could be the drug of choices for treatment of ovarian follicular cysts with similar efficacy. The luteinized cysts generally regress in response to $\mathrm{PGF}_{2 \alpha}$, but the ability to detect whether a cyst is luteinized or not based on palpation alone varies considerably. The cowside progesterone tests may be useful for determining whether a cow is likely to be 
responsive to the above treatment or not, and to confirm the cyclicity or pregnancy (Bajema et al., 1994).

Repeat breeding: Several reports have shown that conception rate in repeat breeding cows (third or later service) can be improved by administration of GnRH (Stevenson et al., 1990) and same with buffaloes (Roy and Prakash, 2009a). The mechanism through which GnRH induces its effect is probably associated with altering progesterone secretion by the corpus luteum rather than by stimulating ovulation, because treatment with $\mathrm{GnRH}$ improves fertility in repeat breeders whereas double insemination does not (Stevenson et al., 1990; Britt, 1995; Mirmahmoudi et al., 2014). If delayed ovulation was a problem in repeat breeders, then double insemination could be one of the practical solutions. And further the user must determine whether the increase in conception rate (about $15 \%$ overall) associated with GnRH treatment of repeat breeders is worth to the extra investment or not. The experimental evidences showed that treatment of repeat breeders with low doses of hCG to increase progesterone level may be more beneficial and cost effective.

\section{Augmentation of reproduction through estrus synchronization protocols along with timed AI}

The accuracy of estrous depends on life cycle of CL and follicular development. The enhanced understanding and innovation of newer treatment regimes to manipulate ovarian follicular growth and corpus luteum regulation over the last two decades has resulted in development of novel Ovsynch protocol (Pursley et al., 1997) for estrus synchronization which is based on elimination of the dominant follicle and initiation of new follicular wave followed by synchronization of ovulation and fixed-time artificial insemination (AI). The technique has also been successfully applied for estrus synchronization and timed AI (TAI) in cows, buffaloes and repeat breeding heifers. Ovsynch and Heatsynch protocol successfully produces pregnancy rates equal to those after detected estrus (cows $37.8 \%$ and heifers $35.1 \%$ ). In general, reproduction in cows and buffaloes are influenced by season, variation in hormonal profiles, nutrition etc; and the fertility is reduced during the period of long day light hours as an effect towards hypothalamohypophyseal-gonadal axis. However, various studies indicated that the majority of acyclic cows and buffaloes exhibit variable degree of ovarian activity, characterized by follicular turn over in one or both ovaries and associated to absence of estrus signs. To rescue acyclic animals, several hormonal protocols have been employed. The estrous cycle in buffaloes can vary from 16 to 28 days and the duration of estrus is typically 8 to 20 hours. They show waves of ovarian follicular development during estrous cycles similar to cattle, and the number of follicular waves during an estrous cycle can vary from 1 to 3 , with 2 waves being the most common. The ultrasonic imaging of cow and buffalo ovaries indicates that size of mature follicles range from approx. 13 to $16 \mathrm{~mm}$ in diameter. As the reproductive efficiency of buffalo is hampered by poor estrus expression, prolonged calving intervals, and delayed maturity, understanding the expression of estrus behaviors and their relationship with the hormonal injections and associated endocrine changes that control estrus are also fundamental for the creation of strategies aimed at improving the detection of estrus and fertility. The estrogen acts as a key regulator of the endocrine and behavioral events associated with the natural estrous cycle and induces estrus behavior, the release of GnRH, LH surge, and finally ovulation. In India, currently, anestrous is one of the major causes of economic losses from both dairy cows and buffaloes. To enhance the reproductive efficiency of buffaloes, during the last two decades several researchers were trying to develop the bio techniques through studying their reproductive endocrinology and ovarian function. For instance, after the development of Ovsynch and Heatsynch protocols in cattle we have successfully performed the same in cross bred cows and buffaloes for synchronization of ovulation and timed artificial insemination (TAI) with a range 
of success in pregnancy rates from $30 \%$ to $40 \%$ (Roy and Prakash, 2008; Roy and Prakash, 2009a; Roy and Prakash, 2009b; Mirmahmoudi et al., 2014; Roy et al., 2018). Further, the new synchronization protocols like Double-synch and Estra-doublesynch (Mirmahmoudi et al., 2014; Bhatta et al., 2017) came into existence by administration of an additional of prostaglandin $\mathrm{F}_{2 \alpha}\left(\mathrm{PGF}_{2 \alpha}\right)$ or estradiol benzoate (EB). It has been found that estradiol benzoate has some advantages compared with GnRH (i.e. cheaper hormone price, easier scheduling and implementation for injection and insemination, greater uterine tone, ease of insemination, and occurrence of estrus). An increase in pregnancy rate after TAI using the Double-synch and Estradouble synch protocol compared with AI after the spontaneous detection of estrus in buffaloes has been reported. Presently, in ICAR sponsored "All India Coordinated Research Project on nutritional and physiological interventions for enhancing reproductive performance in animals", we are finding efficacy of these 'Synch Protocols with TAI' on cows and buffaloes at twelve different centers across India. The different methods of estrus synchronization protocols utilized here are represented in schematic diagram (Fig.1) as follows:

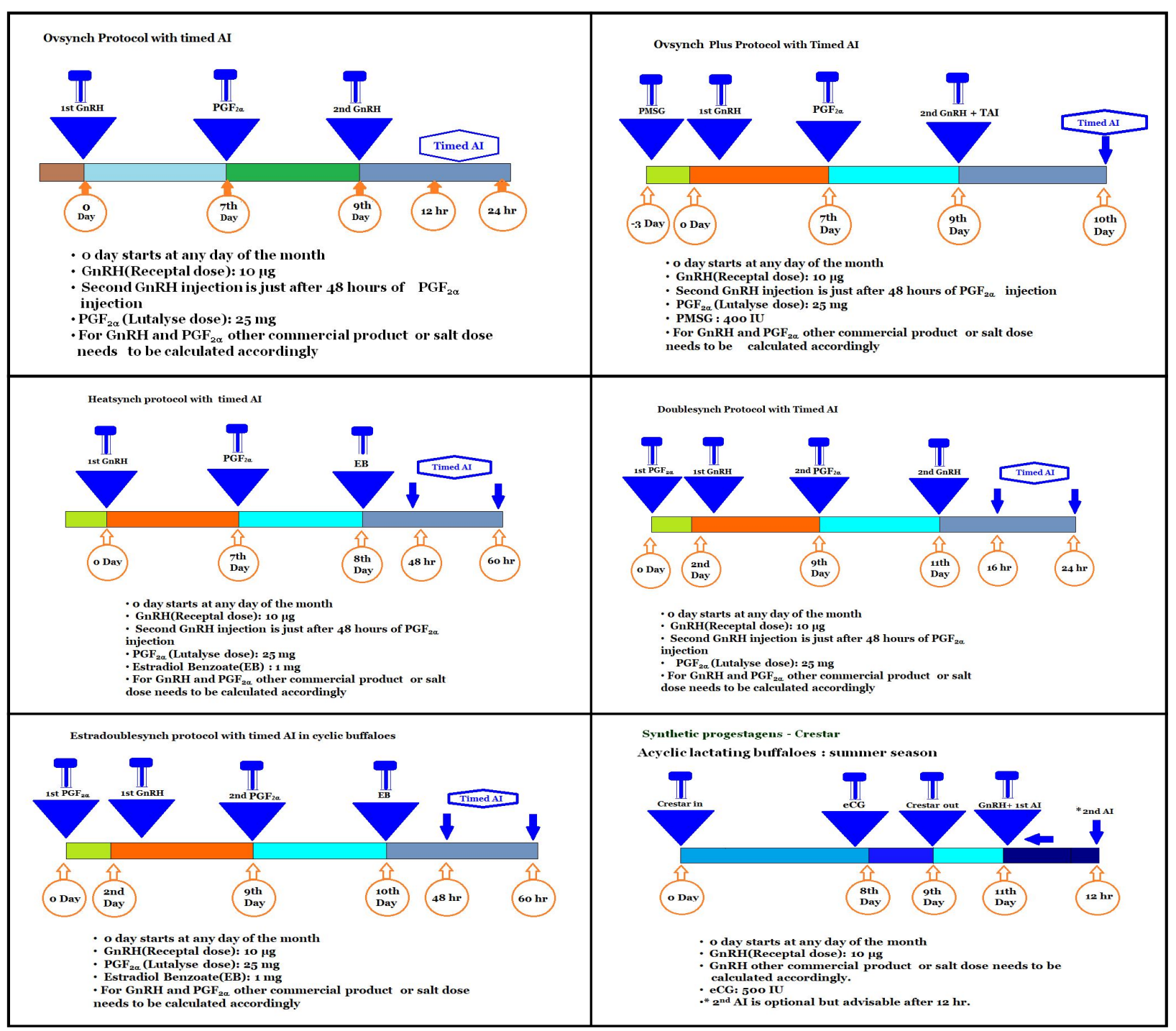

Fig 1. Different synchronization protocol presented in tabular form as ready reckoner 
Cost effectiveness of these 'Synch Protocol' treatments: The approximate cost of treatment (injections + disposables + AI etc.) would be Rs.550/- (for Ovsynch and Heatsynch), Rs. 850/ - (for Doublesynch) and Rs.900/- (for Estradoublesynch). For a cow/buffalo which has been non-pregnant for 6 months the estimated loss to the farmer to bear is approximately Rs. 46800 (and with an assumptions in lower side: cost of milk @ Rs. 200/5 liters/day and feeding cost Rs. 60 per day). Hence the cost benefit ratio would be 51 times (for Ovsynch and Heatsynch), 31 times (for Doublesynch) and 37 times (for Estradoublesynch) with tentative assumption of only $60 \%$ pregnancy success (Bhatta et al., 2017; Roy et al., 2018).

\section{Conclusions}

It is suggested for farmers and livestock producers to have successful reproductive performance and better economic return from their animals, they must implement 'Synch

\section{REFERENCES}

Annual Report-AICRP-NIANP, 2015 to 2019. Annual Report of "AICRP on Nutritional and Physiological Interventions for Enhancing Reproductive Performance in Animals". NIANP, Bangalore; Year (2015-16), (2016-2017), (20172018) \& (2018-2019)

Bajema DH, Hoffman MP, Aitchison TE and Ford SP, 1994. Use of cow-side progesterone tests to improve reproductive performance of highproducing dairy cows. Theriogenol, 42(5): 765771, doi: 10.1016/0093-691X(94)90444-N

Bhatta R, Roy KS, Selvaraju S, Kulasekar KK, Dhami AJ et al., 2017. Doublesynch and Estardoublesynch: Novel and Efficient Strategies for Estrus Synchronization and Fertility Improvement in Livestock. Published by Director, ICAR-NIANP, Bengaluru under AICRP project. (Technical Folder No.-33)

Britt JH, 1991. Impacts of early postpartum metabolism on follicular development and fertility. The protocols' as regular management practices. These protocols are designed to augment the reproductive performance and allow the animals to produce at their maximum potential. By utilizing this reproductive management practices, more animals will be born healthy and breeding animals will become pregnant in a timely manner. But the producers must be cautious of reproductive diseases that can be a deterring factor in the success of reproduction in these animals which in turn may hamper their profit.

\section{ACKNOWLEDGEMENTS}

I heartily acknowledge the readings of several references, original publications and reports from all over the world for this compilation. The interested readers can obtain those further references and suggested readings if interested on request to me. Thanks to ICAR, New Delhi and NIANP, Bangalore for funding me continuously in this fundamental area of research.

Bovine Practitioner Proc, 24: 39, doi: 10.21423/ aabppro19916706

Britt JH, 1995. Achieving a sound reproductive health management programme. Available at: https:// wcds.ualberta.ca/wcds/wp-content/uploads/ sites/57/wcds_archive/Archive/1995/ [1 October 2020]

Butler WR and Smith RD, 1989. Interrelationships between energy balance and postpartum reproductive function in dairy cattle. J Dairy Sci, 72(3): 767-783, doi: $10.3168 / j d s . S 0022-$ 0302(89)79169-4

Canfield RW and Butler WR, 1991. Energy balance, first ovulation and the effects of naloxone on $\mathrm{LH}$ secretion in early postpartum dairy cows. J Anim Sci, 69(2): 740-746, doi: 10.2527/1991.692740x

Etherington WG, Kelton DF and Adams JE, 1994. Reproductive performance of dairy cows following treatment with fenprostalene, 
donoprost or cloprostenol between 24 and 31 days post partum: A field trial. Theriogenol, 42(5): 739-752, doi: 10.1016/0093691X(94)90442-L

Ferry J, 1994. The veterinarian's role: Improving the pregnancy rate. In: Proceedings Natl Reprod Symp, Pittsburgh, PA, Sept 22-23, pp91-102

Garcia A, Barth AD and Mapletoft RJ, 1989. Induction of parturition in the cow: effects of prostaglandin treatment on the incidence of retained placenta. Theriogenol, 31(1): 195, doi: 10.1016/0093691X(89)90603-1

Mirmahmoudi R, Souri M and Prakash BS, 2014. Comparison of endocrine changes, timing of ovulations, ovarian follicular growth, and efficacy associated with Estradoublesynch and Heatsynch protocols in Murrah buffalo cows (Bubalus bubalis). Theriogenol, 82(7): 10121020, doi: $10.1016 / \mathrm{j}$.theriogenology. 2014.07.026

Oltenacu PA, Britt JH, Braun RK and Mellenberger $\mathrm{RW}$, 1983. Relationships among type of parturition, type of discharge from the genital tract, involution of the cervix and subsequent reproductive performance in Holstein cows. J Dairy Sci, 66(3): 612619, doi: 10.3168/ jds.S0022-0302(83)81832-3

Pursley JR, Wiltbank MC, Stevenson JS, Ottobre JS, Varverick HA et al., 1997. Pregnancy rates per artificial insemination for cows and heifers inseminated at a synchronized ovulation or synchronized estrus. J Dairy Sci , 80(2): 295-300, doi: $10.3168 /$ jds.S0022-0302(97)75937-X

Risco CA, Archbald LF, Elliott J, Tran T and Chavatte $\mathrm{P}, 1994$. Effect of hormonal treatment on fertility in dairy cows with dystocia or retained fetal membranes at parturition. J Dairy Sci, 77(9): 2562-2569, doi: 10.3168/jds.S00220302(94)77197-6

Roy KS and Prakash BS, 2008. Efficiency of ovsynch treatment for improvement of cyclicity in Murrah buffalo heifers during summer stress. Ind Vet J, 85(8): 833- 836

Roy KS and Prakash BS, 2009a. Changes in endocrine profiles during ovsynch and ovsynch plus norprolac treatment in Murrah buffalo heifers at hot summer season. Trop Anim Health Prod, 41(4): 677-687, doi: 10.1007/s11250-0089241-3

Roy KS and Prakash BS, 2009b. Plasma progesterone, estradiol-17 $\alpha$ and total estrogen profiles in relation to estrous behavior during ovsynch treatment in Murrah buffalo heifers. J Anim Physiol Anim Nutr, 93(4): 486-495, doi: 10.1111/j.14390396.2008.00830.x

Roy KS and Collier RJ, 2012. Regulation of acclimation to environmental stress. In: Environmental Physiology of Livestock (Collier RJ, Collier JL, eds). Wiley- Blackwell Publication,Ames,Iowa(USA), pp49-63

Stevenson JS, Call EP, Scoby RK and Phatak AP, 1990. Double insemination and gonadotropinreleasing hormone treatment for repeat breeding dairy cattle. J Dairy Sci, 73(7): 1766-1772, doi: 10.3168/jds.S0022-0302(90)78855-8

Web link: Animal Reproduction Management. Available at: https://www.mishicotffa.org/ uploads/2/3/2/7/23271034/repro_problems.pdf [25 September 2020] 